\title{
ITINERANTES E CITADINOS: A COMPANHIA DE TEATRO COIMBRA E SUAS INTERAÇÕES COM A POPULAÇÃO DE DIAMANTINA/MG
}

\author{
Ronaldo Flaviano de Souza Junior ${ }^{1}$
} Renata Cristina Simões de Oliveira ${ }^{2}$

Recebido em: 11/11/2020

Aprovado em: 14/12/2020

\begin{abstract}
Resumo: O Teatro de Santa Izabel foi, ao longo da segunda metade do século 19, um dos principais espaços de divertimento da cidade de Diamantina/MG. A presença da Companhia Coimbra no ano de 1899, no entanto, chama a atenção não só pelo tempo em que esteve na cidade, mas pelos constantes noticiários carregados de elogios por sua atuação. Assim, este estudo analisa a presença da Companhia Coimbra na cidade durante o ano de 1899, não só na perspectiva das apresentações realizadas no teatro em questão, como também suas demais contribuições à população local ao longo dos nove meses em que estiveram na cidade. Constatando que além de beneficiar na manutenção das atividades públicas de diversão, a companhia contribuiu inclusive com instituições locais e com o aprendizado de parte da população para a atuação no campo teatral. A análise foi feita a partir da consulta dos periódicos de circulação no município, os quais se encontram disponíveis em arquivo físico, na Biblioteca Municipal Antônio Torres, e digital no Arquivo Público Mineiro, bem como consultas à memorialistas diamantinenses.
\end{abstract}

Palavras-chave: Teatro; Divertimentos; Diamantina/MG; Companhias Itinerantes; Companhias Amadoras.

\section{ITINERANTES Y CIUDADANOS: LA COMPAÑÍA DE TEATRO COIMBRA Y SUS INTERACCIONES COM LA POBLACIÓN DE DIAMANTINA / MG}

Resumen: El Teatro de Santa Izabel fue, durante la segunda mitad del siglo XIX, uno de los principales espacios de entretenimiento en Diamantina / MG. La presencia de Companhia Coimbra en el año 1899, sin embargo, llama la atención no solo por el tiempo que estuvo en la ciudad, sino también por las constantes noticias llenas de elogios por su actuación. Así, este estudio analiza la presencia de Companhia Coimbra en la ciudad durante el año 1899, no solo desde la perspectiva de las presentaciones realizadas en el teatro en cuestión, sino también sus demás aportes a la población local durante los nueve meses que estuvieron en la ciudad. Consciente de que además de beneficiarse del mantenimiento de las actividades de entretenimiento público, la empresa también contribuyó con las instituciones locales y con el

\footnotetext{
1 Doutorando em Estudos do Lazer / UFMG, bolsista CAPES. Bacharel em Turismo. E-mail: souzajr.ronaldo@gmail.com. ORCID: https://orcid.org/0000-0001-5991-5158.

2 Doutoranda em Estudos do Lazer/UFMG, bolsista FAPEMIG. Bacharel em Turismo/UFVJM. E-mail: renatinhacrso@hotmail.com. ORCID: https://orcid.org/0000-0003-2682-1934.
} 
aprendizaje de parte de la población para la actuación en el ámbito teatral. El análisis se realizó mediante la consulta de los diarios de circulación en el municipio, que se encuentran disponibles en archivos físicos, en la Biblioteca Municipal Antônio Torres, y digitales en el Arquivo Público de Mineiro, así como consultas con memoriales diamantinenses.

Palabras clave: Teatro; Diversiones; Diamantina/MG; Compañías Itinerantes; Compañías de Aficionados.

\title{
ITINERANTS AND CITIZENS: THE THEATER COIMBRA COMPANY AND ITS INTERACTIONS WITH THE POPULATION OF DIAMANTINA / MG
}

\begin{abstract}
The Theater of Santa Izabel was, throughout the second half of the 19th century, one of the main entertainment spaces in Diamantina / MG. The presence of Companhia Coimbra in the year 1899, however, stands out not only for the time they were in the city, but for the constant praiseworthy news for their performances. Thus, this study analyzes the presence of Companhia Coimbra in the city during the year 1899, not only from the perspective of the presentations made in the theater in question, but also its other contributions to the local population over the nine months that they were in the city. Realizing that in addition to benefiting from the maintenance of public entertainment activities, the company also contributed with local institutions and with the learning of part of the population for acting in the theater field. The analysis was made by consulting the circulation journals in the municipality, which are available in physical files, at the Biblioteca Municipal Antônio Torres, and digital in the Arquivo Público Mineiro, as well as consultations with diamantinenses memorialists.
\end{abstract}

Keywords: Theater; Amusements; Diamantina/MG; Itinerant Companies; Amateur Companies.

\section{Introdução}

Diamantina vivia na década de 1890 a euforia da "belle époque": Possuía iluminação a querosene, abastecimento de água potável, calçamento nas ruas centrais, o Teatro Santa Isabel, biblioteca pública, diversas bandas de música e grêmios literários, um parque municipal no largo da Cavalhada Velha. Eram muitos os saraus realizados nas casas das famílias de destaque e, nas primeiras décadas do século $\mathrm{XX}$, a cidade chegou a ter salão de boliche, pista de patinação, dois cinemas, loja de aluguel de bicicletas, clubes recreativos (LOBATO, 2000, p. 191).

Pode-se dizer que no período citado acima, Diamantina se apresentou como uma cidade na qual a diversão era vivenciada em diferentes espaços, de formas diversas e por diferentes sujeitos. Nesse período, a imprensa local, fortalecida por questões políticas, levava ao leitor discursos de melhorias urbanas e de modernização dos costumes. O discurso de modernização era dirigido à infraestrutura urbana, aos projetos sanitaristas e também aos divertimentos, às artes e à cultura. 
Assim como o que ocorreria em outras localidades, como é demonstrado por Melo e Marzano em seu estudo sobre as diversões no Rio de Janeiro entre 1830 e 1930, em Diamantina os "intelectuais e autoridades defendiam que as diversões da cidade - não só nas praças como também nos teatros e outros espaços - deveriam atestar o seu grau de civilização" (MARZANO e MELO, 2010, p. 13). As "peças de teatro, modas e costumes, artefatos e mecanismos eram apresentados a Diamantina, com grande destaque dado ao seu caráter moderno e civilizado" (GODWIN JUNIOR, 2015, p. 73). O aspecto instrutivo e útil dos divertimentos era dado como justificativa para que a sociedade os vivenciasse.

Nos anos finais da década de 1880 o teatro ganhou destaque nas páginas dos jornais entre os demais divertimentos presentes em Diamantina. A esse era atribuída uma contribuição na formação moral civilizada, ao passo que "constituía um ponto de encontro entre as pessoas, efervescendo um campo de exercício das regras de comportamento em sociedade" (DUARTE, 1995, p. 139). Os jornais passaram a noticiar a chegada de companhias na cidade, a sua atuação, o conteúdo das apresentações, o sucesso ou fracasso frente à plateia, as críticas e os detalhes das apresentações. O público era convidado e aconselhado a dar assistência e acolhida a esta "difícil" e "útil" arte.

Dessa forma, os discursos produzidos nesses periódicos servem como balizador para as reflexões do presente artigo. Em sua maioria, eles eram distribuídos semanalmente e de alcance regional, sendo compostos por quatro páginas, salvo algumas edições especiais que chegavam a cinco ou seis páginas. Portanto, foi eleito o jornal O Município, único que esteve em circulação na cidade de Diamantina dentro do período que esta pesquisa aborda. Assim, as fontes que versavam sobre a Companhia Coimbra foram tabuladas, transcritas, separadas em categorias e posteriormente analisadas.

\section{O Teatro no Cotidiano Diamantinense}

Tia Aurélia ontem mandou convidar a família para ir lá jantar. Fomos. Era aniversário dela e as filhas quiseram festejar com um teatro. Fizeram um palco de verdade e elas e os irmãos representaram como se fossem atores. Representaram muito bem e com muita graça. Tio Conrado ficou como um peru de inchado com o teatrinho dos meninos. Eu tive pena foi de tia Agostinha que tinha feito também na semana passada uma ceia para o teatrinho de Lucas e ficou desapontada vendo a diferença dele para os dos filhos de tio Conrado. Ontem eles decoraram uma peça e representaram tudo como se fosse dentro de uma casa. João Afonso era o marido, Beatriz a mulher, Sérgio era o hóspede e Hortênsia a criada. Leontino era o cavalo de judeu que mudava a mesa e tirava as flores.

No teatro de Lucas ele pôs um lençol no escuro e pregou uma porção de bonecos. Vinha depois com uma vela e fazia os bonecos dançarem. Depois 
Nico virou cambotas no palco. No fim ele chamou Emídio e perguntou se queríamos ver um negro virar branco, e virou farinha de trigo na cara de Emídio. Depois ele ainda fez uma coisa que aprendeu com o palhaço, quebrou um ovo na cabeça de Emídio.

O teatro de Lucas foi só dessas bobagens, e tia Agostinha estava achando muito engraçado. Ontem ela viu que o dos outros primos era muito mais importante e ficou com inveja. Tia Aurélia vive fazendo inveja às outras (MORLEY, 1999, p. 61-62).

A partir do trecho destacado, é que se inicia a fala acerca do teatro em Diamantina, demonstrando assim que o teatro se demonstrou um importante espaço divertimento dos moradores da cidade, uma vez que, como apontado por Veneziano (1991, p. 15), ele foi "o mais expressivo e fervilhante gênero nas primeiras décadas desse nosso ruidoso século XX”. Seja nos momentos de informalidade com as representações familiares, como o ocorrido na casa da Tia Aurélia, até a ida de companhias teatrais para se apresentarem na cidade, as referências às dramatizações são, sem dúvida, um dos tópicos mais recorrentes nos jornais da cidade.

As apresentações realizadas pelos filhos de Aurélia com as de Agostinha são capazes de demonstrar que momentos como esses eram um método comum para animar as sociabilidades nas casas das famílias da Diamantina. O contraponto existente entre as encenações demonstra que essas poderiam ocorrer de modo mais informal, como aparentemente foram aquelas realizadas por Lucas, em que o tom humorístico era a atração principal, ou mesmo mais elaboradas como a história representada por João Afonso, Beatriz, Sérgio e Leontino em que houve inclusive a preocupação na montagem de um palco, bem como a de dedicar uma pessoa para ser o responsável pelas mudanças dos cenários.

Momentos como esses se estendiam inclusive para o cotidiano das crianças, que a partir do improviso davam asas à imaginação e criavam histórias durante suas brincadeiras: "nós fizemos no fundo da horta, uma casinha de capim para servir de teatrinho de bonecos. Cada um fez um boneco e saíram tão mal feitos que nós rimos a perder, de vê-los representar (MORLEY, 1999, p. 32)". Mesmo que a casinha que serviu de cenário fosse feita de capim, e os bonecos estivessem sido mal feitos, percebe-se nas crianças certo ímpeto em fazer com que a brincadeira acontecesse de forma semelhante às que aconteciam nos teatros profissionais. Inclusive a comercialização da brincadeira esteve em pauta, uma vez que "Nico disse que se ele saísse para a rua anunciando, poderiam aparecer os meninos da cidade (MORLEY, 1999, p. 32)”, o que só não foi feito porque "ele sabe que vovó e as tias não consentiriam em amontoar gente no quintal, passando por dentro de casa (MORLEY, 1999, p. 32)”.

Tal impedimento fez com que as crianças se limitassem apresentar o teatro dos bonecos apenas para as pessoas da família, o que de alguma forma rendeu algum lucro para os mesmos, 
tendo em vista que mediante ao pagamento da entrada de cem réis, eles conseguiram arrecadar um total de mil e seiscentos. Essa arrecadação nos leva a crer que momentos como esses eram incentivados pelos adultos, os quais podiam inclusive se divertir, como se pode perceber a partir da descrição feita por Helena do comportamento do seu tio Conrado que ficou até vermelho de tanto gargalhar durante a encenação ocorrida na festa de aniversário de Aurélia.

As crianças não eram as únicas que se propunham a encenar nos divertimentos domésticos, como foi o caso descrito por Helena ao ser convidada para ir até a casa do senhor Benfica para assistir ao teatro de fantoches realizado pelo mesmo. Na situação ela descreve como foi a noite: "Que noite boa! Nunca vi coisa mais engraçada que a dança daqueles bonecos. Parece gente. Então os dois, Briguela e Maricota, são impagáveis. A gente fica até duvidando que sejam bonecos". O ato de reunir pessoas para a apresentação dos fantoches era algo comum na casa do Benfica, tendo em vista que esta já seria a segunda vez que Helena pôde participar, aliado ao desejo da menina de poder ir sempre: "Era bem bom se eu pudesse ir todos os dias. Seu Benfica me perguntou se eu gostei e respondi: 'Demais!'. Ele então prometeu que vai me levar mais algumas noites. Gostei de ele dizer "algumas". Podia ter dito 'mais uma' (MORLEY, 1999, p. 27-28)".

As reuniões para apresentações teatrais de forma amadora aconteciam de forma até mesmo mais elaboradas como fora noticiado no jornal A Idea Nova um espetáculo organizado pela professora Edésia Corrêa Rabello na casa de Catão Junior. Na ocasião, os alunos da docente, previamente ensaiadas por ela, apresentaram "representações de comédia, monólogos, cançonetas, etc. ${ }^{3}$ ". Na descrição do evento, foi demonstrado a preocupação em organizar o ambiente para receber os convidados, ocorrido na sala de visitas, o qual estava ornado com "flores em abundancia notável esparsas aos ramalhetes em todo canto que formavam um conjunto chic", e que "ao fundo erguia-se um bem arranjado palco, que com o panno descia as cortinas e fitas pendentes 5 ". Mesmo com as 78 cadeiras espalhadas pelo ambiente, foi descrito que ainda assim algumas pessoas ficaram de pé, demonstrando assim a ampla concorrência de expectadores.

Esses movimentos em torno do teatro no cotidiano das pessoas certamente contribuíram para que grupos buscassem maior profissionalização dos seus espetáculos, tendo em vista que havia na cidade diversas companhias de teatro amador, as quais frequentemente se

\footnotetext{
${ }^{3}$ Festa Infantil. A Idea Nova. Diamantina, 18 de Novembro de 1906, p.3.

${ }^{4}$ Ibd.

${ }^{5} \mathrm{Ibd}$.
} 
apresentavam nos mais variados espaços. Sobre o teatro amador, Prado (2001, p. 38) destaca que essa era uma prática comum nesse período:

\begin{abstract}
A ação renovadora do amadorismo não é fato incomum na história do teatro. Assim aconteceu na França, com Antonie, e na Rússia, com Stanislavski, para que o naturalismo pudesse brotar e florescer. Assim aconteceu nos Estados Unidos, com os Provincetown Players, para que Eugene O'Neill reformulasse a dramaturgia americana. $\mathrm{O}$ ciclo em linhas gerais se repete: um teatro excessivamente comercializado; grupo de vanguarda que não encontram saída a não ser à margem dos palcos oficiais, tendo sobre estes a vantagem de não necessitar tanto da bilheteria para sobreviver; a formação de um público jovem que, correspondendo melhor às aspirações ainda mal definidas do futuro, acaba por prevalecer, e o ressurgimento triunfal do profissionalismo, proposto já agora em bases diversas, não só artísticas mas ás vezes até mesmo econômicas e sociais.
\end{abstract}

Assim como em outros lugares do mundo, as companhias amadoras de Diamantina, como apontado por Oliveira (2016), exerceram papel fundamental na cidade no sentido de oferecer certa continuidade na oferta de espetáculos da cidade, principalmente entre o período de saída de uma companhia ambulante até a chegada de outro. Nesse sentido, essas companhias inclusive chegaram a ser incentivadas pelo poder público ao ser promulgada uma lei no dia 16 de julho de 1896 que visava o poder público contribuir com a quantia de seiscentos mil réis "a qualquer companhia dramática que se crear nesta cidade e que levar á scena uma serie de doze espetáculos públicos, no decurso de um anno ${ }^{6}$ ".

No domingo passado estreou no Theatro Santa Isabel a Companhia Diamantinense de Amadores, sob a direcção dos srs. Assis Moreira e Cosme do Couto.

Representaram com grande êxito o drama Um erro judiciário e a hilariante comedia As duas gatas, uma verdadeira fabrica de gargalhadas.

Os dous diretores foram incasaveis para o bom exito do espectaculo e conseguiram proporcionar ao nosso publico horas muito agradaveis.

Hontem houve repetição, a pedido de diversas famílias?

Tomando como base a referência da solicitação por uma nova apresentação, pode-se inferir que tais divertimentos agradavam inclusive ao público expectador, ademais, não era incomum encontrar nos jornais notas que teciam diversos elogios tanto para as apresentações no geral, como para os atores e diretores - "Não desfazendo nos demais amadores, que de nós, so merecem os maiores encômios, não podemos omitir os nomes do Cosme, Assis, Laport, d. Sinhá e senhorita Maria de Aguillar, que mais uma vez, souberão tão bem interpretar o difficil papel que lhe foi confiado" ${ }^{8}$.

\footnotetext{
${ }^{6}$ Theatro. O município. Diamantina, 06 de agosto de 1896, p.1.

${ }^{7}$ Theatro. A Idea Nova, Diamantina, 21 de junho de 1908, p.1.

${ }^{8}$ Theatro Santa Isabel. O Município.Diamantina, 18 de novembro de 1903, p.3.
} 
Como na nota acima destacada, era comum a citação de mulheres compondo o corpo de atores nos espetáculos, demonstrando essa ser uma prática habitual para ambos os sexos. Sobre a presença das mulheres nos palcos, no geral, essa não era uma atividade bem vista pela sociedade da época, como apontado por Andrade e Bulhões (2008) ao apontarem que em razão do forte preconceito que rondava a profissão de atriz, considerada até mesmo, em determinados casos, uma variante do exercício da prostituição, orientava que essa era uma atividade permitida somente para as mulheres que já faziam parte daquele mundo. Entretanto, aparentemente essa visão não estava de acordo com a visão dos moradores de Diamantina, tendo em vista os frequentes elogios às atrizes, fossem elas solteiras, quando referidas como senhoritas, ou mesmo casadas, quando utilizado o pronome senhora.

Os jornais, com certa frequência noticiavam a presença de mulheres atuando nas peças teatrais amadoras, entretanto, quase que na totalidade os diretores citados eram homens, salvo em apresentações que visavam fins de caridade - "Um grupo de distinctas senhoritas diamantinenses pretende levar a efeito, brevemente, nesta cidade, a representação de um magnifico drama sacro, em favor das obras da capella de Santo Antonio dos Pobres"'. A realização de espetáculos para fins de caridade era algo bastante comum no cotidiano local, e assim como os locais, era hábito inclusive que as companhias vindas de outras cidades também destinassem ao menos um dia de bilheteria a alguma organização da cidade:

"Para prova de sua gratidão, estimulado pelo amor ao bem, e pelo pedido da benemérita comissão que rem sobre seus hombros a gloriosa empresa da fundação de um Asylo de Invalidos nesta cidade, resolveu o nobre artista trabalhar no ultimo espetáculo, consagrando o fructo do mesmo em beneficio do Asylo ${ }^{10 \prime}$.

Por falar em caridade, é preciso ressaltar inclusive que o principal espaço reservado para tal fim foi construído a partir da iniciativa dos gestores da Santa Casa de Caridade, então gerida pela Irmandade de Santa Isabel, um grupo católico formado por pessoas que contribuíam periodicamente com donativos previamente estipulados. Assim, foi fundado no ano de 1841 o teatro Santa Isabel no Largo do Rosário.

\footnotetext{
${ }^{9}$ Drama Sacro. A Idea Nova. Diamantina, 13 de março de 1910, p.1.

${ }^{10}$ Antonio Coimbra. O Município. Diamantina, 02 de outubro de 1899, p.1.
} 
Figura 1 - Teatro Santa Isabel

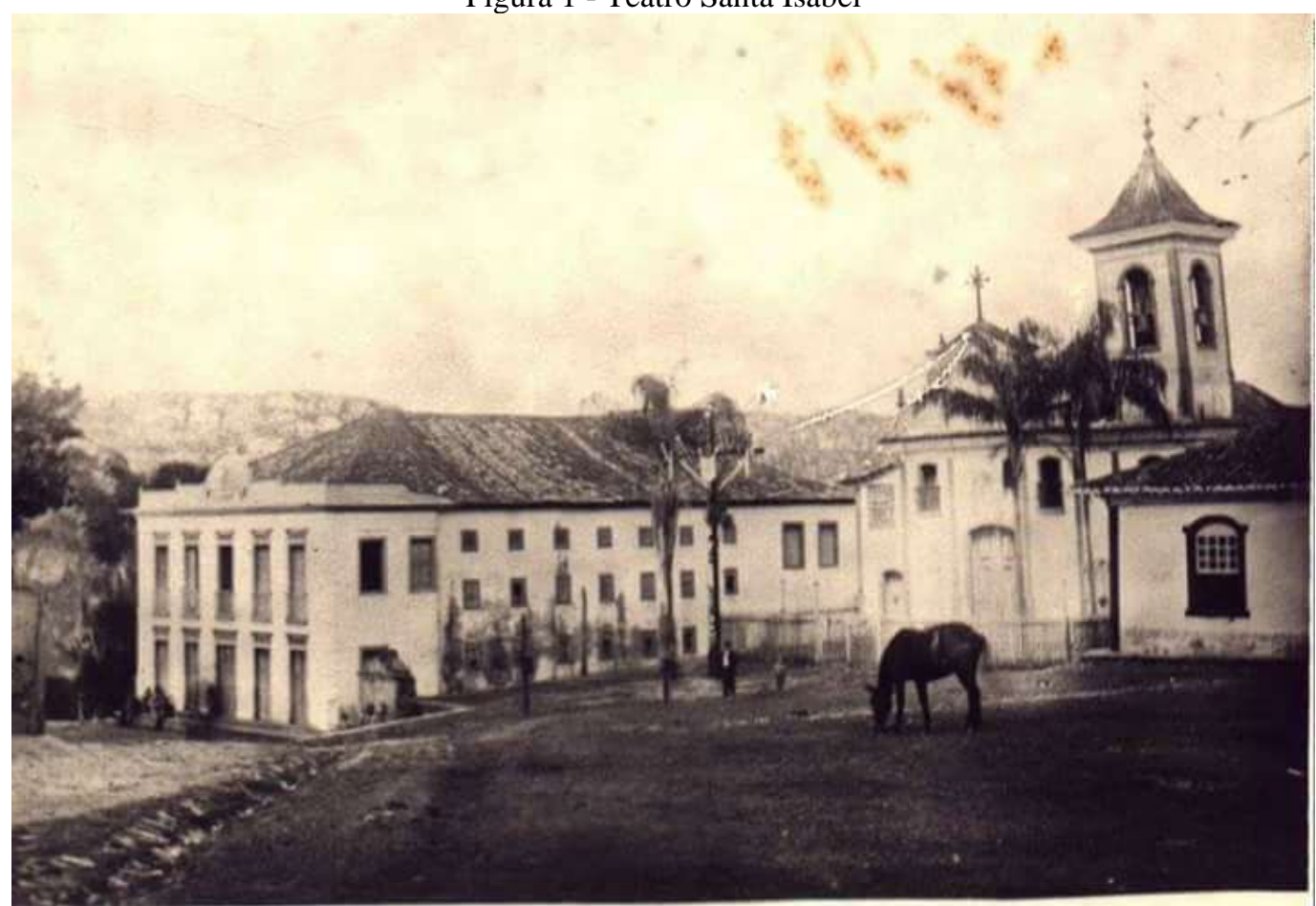

Fonte: http://santacasadediamantina.com.br/index.php/home/fatos-historicos.html

De início foi construído um prédio simples, mas que com o aumento da demanda de espectadores o mesmo passou por diversas reformas como o aumento do número de acentos, a construção de camarotes e sua ampliação a fim de melhor atender ao público ficando da forma como se pode ver na imagem acima. Mesmo que neste espaço houvesse uma regular assiduidade de apresentações, as quais eram noticiadas quase sempre ressaltando a ampla frequência de pessoas o teatro ali funcionou até o ano de 1912 quando a partir de um acordo entre o Governo do Estado de Minas, a Câmara Municipal de Diamantina e sua irmandade gestora o prédio foi demolido a fim de dar lugar a uma cadeia pública e o mesmo transferido para um prédio recém construído para tal fim localizado na rua Direita da cidade.

Acerca dos estilos que mais frequentemente eram representados nos teatros brasileiros dessa época, Braga (2003) nos esclarece que o drama, comédias e melodramas eram os mais frequentes. A autora ainda nos esclarece que "nos dramas foram abordados os conflitos vivenciados pela sociedade naquele momento, ao passo que a comédia preservava a tradição da crítica debochada dos costumes iniciados nos primórdios do Império, além de terem assimilado novos padrões da graça cotidiana, ao passo que o melodrama trazia à tona o gosto popular pela emoção servida às escâncaras. Além dos estilos citados, ocorriam nos palcos da cidade apresentações destinadas às crianças, como o teatro de fantoches a exemplo da companhia dirigida por Henrique Fornero que esteve em temporada em Diamantina no ano de 1915, que 
segundo o A Estrella Polar "tem fornecido ao publico boas noitadas, fazendo o impagável Briguella as delicias da meninada que não cessa de aplaudir as suas diabruras ${ }^{11}$ ”.

Assim como encenações teatrais nos moldes em que conhecemos atualmente, os palcos da época traziam uma multiplicidade de espetáculos com variados números artísticos, os quais não haviam atores representando um texto. Esse gênero comumente chamado de variedades possuíam também os elementos tradicionais do teatro com palcos, o teatro enquanto espaço físico e a apresentação de um artista, que não era necessariamente um ator, tendo em vista que as apresentações se baseavam nas suas habilidades como o contorcionismo, números de mágica, dentre outros - " é esperado, brevemente, nesta cidade, o celebre Clemente Page, que, com variados trabalho de prestidigitação, ilusão physica, optica, magnetismo, ventriloquia e magia, tem alcançado grande sucesso nos theatros da Europa e da America ${ }^{12}$ ".

Como se pode ver, os palcos eram ocupados tanto por companhias locais como a de vindas de outras cidades, as quais eram quase sempre elogiadas a partir da atuação, bem como a partir da beleza dos cenários e indumentárias, como noticiado pelo jornal O Município ao se referir às apresentações realizadas pelo artista John Bridges: "O scenario montado com luxo e capricho e os seus ricos vestuarios deram-lhe grande realce ${ }^{13}$ ". Essas companhias de certa forma levavam à algumas pessoas uma sensação de civilização e progresso, tendo em vista que as companhias ou seus espetáculos faziam referência a apresentações realizadas em outras cidades ou fazem referência à encenação de peças semelhantes em outros lugares.

A peça, que finalisa com lindissima apotheose e teve grande acceitação em Pariz, no theatro Olympo, foi arranjada para transformações pelo hábil artista. Nós que temos conhecido vários e notáveis artistas no genero, com franqueza, dizemos, a nenhum delles podemos igualar o Sr. Bridges, que na nossa humilde opinião, os excede, no original trabalho de transformismo, não só pela sua incrível rapidez, como pela pericia com que representa sosinho comedias, dramas, melodramas, scenas-comicas, cantando tenor, barytono, meio-soprano e contralto.

O publico diamantinense, applaudindo-o com desusado enthusiasmo, nada mais fez jus ao mérito e nós nada mais que o juízo sobre elle feito pela imprensa carioca, rio-grandense, bahiana, paulista e mineira ${ }^{14}$.

\section{O Senhor Coimbra e Sua Companhia}

Precedente da cidade de Ouro Preto, chegava em Diamantina a Companhia Dramática Coimbra, um grupo de teatro itinerante, que carregando, em boa parte do trajeto, sob o dorso

\footnotetext{
${ }^{11}$ Fantoches. A Estrella Polar. Diamantina, 26 de dezembro de 1915, p.2.

12 Illusionista. Pão de Santo Antonio, Diamantina, 03 de junho de 1917, p.3.

13 Theatro Santa Isabel. O Município, Diamantina, 21 de fevereiro de 1903, p.2.

${ }^{14}$ Theatro Santa Isabel. O Município. Diamantina, 21 de fevereiro de 1903, p.2.
} 
de animais uma vasta bagagem contendo variadas indumentárias bem como um abundante número de cenários e equipamentos. Sob a direção de Antonio José Duarte Coimbra Junior, o qual fora acompanhado por sua esposa Hermínia, sua filha Sofia com seu marido Luiz Bitencourt, bem como Gustavo Mercandier, o cenógrafo, Agostinho Pedra, secretário e João Gonçalves Lessa e sua esposa Leodegardia.

Pouco se sabe a respeito das origens deste grupo, entretanto, foi possível constatar que o seu fundador, Antonio Coimbra era natural de Recife, onde nascera em 1852. De acordo com nota de José Teixeira Neves publicada no periódico Pão de Santo Antonio, o diretor "abandonou, na mocidade, pelo palco, a faculdade de direito onde cursava o primeiro ano"15. Os trabalhos que se propõe a analisar acerca do teatro nacional pouco falam sobre ele, o que não acontece com seu pai, Antonio Jose Duarte Coimbra, o qual frequentemente é mencionado como referência no meio teatral do Recife. Souza Bastos (1898) ao fazer referência ao pai, cita a existência de um filho que andava em excursão pelo interior do país, com uma companhia dramática, sem identifica-lo.

A partir de pesquisas feitas em variados jornais da época ${ }^{16}$, foi possível identificar diversas referências ao Coimbra Junior em espetáculos. O primeiro indício que se têm é de um anúncio veiculado no jornal A Província ${ }^{17}$, no Recife, em que o então ator é citado dentre diversos outros numa apresentação no Teatro Santo Antonio, de propriedade do seu pai, o qual fora realizado no dia 12 de agosto de 1874 . Se em momento posterior o seu nome somente fora citado dentre os demais colegas de profissão, no ano de 1877 encontrou-se anúncio em que o mesmo era apontado como o beneficiado do espetáculo, no teatro de propriedade do seu pai, fato que foi possível identificar outras vezes no mesmo jornal até a data de 28 de agosto de 1880:

Quarta-feira 12 do corrente Espetaculo em beneficio do actor Antonio José Duarte Coimbra Junior. Representar-se-há o drama em 8 actos, intitulado:

O Grilheta de Botany-bay e a chistosa e muito aplaudida comedia O Conde de Paragará.

Em obsequio ao beneficiado tomara parte em todo o espetaculo o proprietário do mesmo theatro, o Sr. Antonio José Duarte Coimbra ${ }^{18}$.

\footnotetext{
${ }^{15}$ Companhia Coimbra. Pão de Santo Antonio, Diamantina, 25 de maio de 1923, p.2

${ }^{16}$ Tais periódicos se encontram disponíveis para consulta online na Hemeroteca Digital Brasileira, nos qual foram feitas pesquisas a partir da localização digital de termos inserindo as possíveis variações do nome do ator em questão.

${ }^{17}$ Espetáculo. A Província. Recife, 11 de agosto de 1874, p.3.

18 Theatro Santo Antonio. Jornal do Recife. Recife, 06 de dezembro de 1877, p.2.
} 
Foi somente no ano de 1890 que se encontrou a primeira referência à Companhia Coimbra, no qual o jornal $O$ Republicano ${ }^{19}$ de Aracajú, no Sergipe, anuncia alguns espetáculos realizados na cidade entre os meses de junho e julho deste ano. No ano seguinte, aparece também referências à presença do grupo em Maceió entre os meses de julho a outubro, veiculados pelo periódico Cruzeiro do Norte.

Em 1892, consta nos Atos Oficiais publicado no Jornal do Recife uma solicitação em que o Coimbra solicitava ao governo do estado a possibilidade de fazer trabalhar uma companhia dramática, a qual era diretor, no Teatro Santa Isabel da cidade em questão, o que fora negado. Mesmo com a negativa, houve uma referência, veiculada no Diário de Pernambuco $^{20}$ de que a referida companhia se apresentou nesse teatro por duas vezes no mês de agosto. Apesar das dificuldades em se manter as apresentações em um dos principais estabelecimentos teatrais da cidade, no ano subsequente aparece nota em que o diretor em questão fizera a mesma solicitação anteriormente mencionada, a qual dessa vez foi concedida:

Concêdo durante o tempo em que estiver desocupado o theatro «Santa Isabel», ficando salvo o governo o direito de contractar alguma outra companhia que em melhores condições se apresentar devendo a inspectoria, no fim de alguns espetáculos, dar o seu juízo por escripto acerca do merecimento artístico da companhia, não só quanto ao elenco como tambem em relação ao repertorio ${ }^{21}$.

Dessa forma, o Jornal de Recife ${ }^{22}$ anunciava a apresentação de estreia da companhia anunciando uma grande novidade teatral com a representação do espetáculo Os Rabichos a ser relizada numa quinta-feira, 12 de janeiro. Apesar da aparente expectativa, tal apresentação não aconteceu, visto que fora proibida pela polícia com o argumento de que a mesma falava sobre "positivismo e por sua inoportunidade ${ }^{23}$ ". Dado o adiamento da estreia, o espetáculo foi substituído pelo drama A Douda dos Pyrineus, o qual estava previsto para ser relizado no dia 19 de janeiro. A partir de então não apareceram mais indicações das apresentações dirigidas por Antonio Coimbra no Teatro Santa Isabel, nem mesmo nenhuma referência se de fato tal apresentação aconteceu.

Ao se analisar a nota de concessão do Teatro Santa Isabel à companhia, pode-se perceber a pouca notoriedade que o grupo recebia no cenário local, dado o certo receio apresentado, tendo em vista que a mesma somente poderia ocupar o espaço até que aparecesse um outro grupo que apresentasse melhores condições de ofertar espetáculos, somado ao fato de prévias

\footnotetext{
${ }^{19}$ Pescador de Baleias. O Republicano. Aracaju, 15 de junho de 1890, p.2.

${ }^{20}$ O Drama 89. Diário de Pernambuco. Recife, 13 de Agosto de 1892, p. 2.

${ }^{21}$ Jornal do Recife. Recife, 4 de janeiro de 1893, p.2.

${ }^{22}$ Jornal do Recife. Recife, 11 de janeiro de 1893, p.1.

${ }^{23}$ Os Rabichos. Jornal do Recife. Recife, 12 de janeiro de 1893, p.03.
} 
análises acerca dos atores, bem como das cenas a serem representadas, o que de fato foi cumprido, dada a censura feita no espetáculo de estreia.

Tais fatores leva a crer que a então companhia não conseguiu lograr grandes êxitos, ao menos em Recife, tendo em vista a ausência de referências nos jornais da cidade, o que é corroborado com nota emitida no Jornal do Recife em que conta os nomes de Antonio Coimbra, sua mulher e 2 filhos dentre as listas de passageiros no trem que ia em direção ao sul de Pernambuco em 19 de julho. Foi somente em 8 de setembro do ano seguinte em que o nome do ator aparece novamente, mas dessa vez dentre os passageiros recém-chegados do trem vindo do norte do estado. Seu retorno e o de sua esposa estava atrelado às apresentações que seriam realizadas pela Companhia Apollonia Pinto em breve turnê ocorrida durante o mês de setembro e outubro.

Apesar das apresentações feitas em outro grupo, aparentemente a Companhia Coimbra continuou com suas apresentações tendo em vista que novas referências continuaram a surgir, desta vez em Manaus, no ano de 1895 com apresentações em dezembro e janeiro do ano seguinte, como noticiado pelo A Federação. A Companhia também se fez presente na capital da Paraíba, em maio de 1896, como noticiado pelo Jornal do Brasil. Desta forma, percebe-se que o senhor Coimbra e seu grupo começaram a realizar apresentações em diversos estados do país, até chegar em Diamantina, em 1899.

\section{A Companhia em Diamantina}

Estreou no theatro desta cidade, na noite de 15, com uma esplendida casa, a companhia dramática, dirigida pelo actor Coimbra. O sr. Coimbra escolheo em seu repertorio, para estrea, o drama em 5 actos de D'Ennery - A Tomada da bastilha ${ }^{24}$.

Como se pode notar no anúncio, a Companhia Coimbra chegou a Diamantina em janeiro de 1899, a qual teve em sua estreia a apresentação de um drama baseado no evento histórico francês, A Queda da Bastilha. Cabe ressaltar que no ano anterior à chegada do grupo de artistas, não foram encontradas referências nos periódicos locais que fizessem menção a apresentações de quaisquer companhias teatrais no teatro Santa Isabel, no entanto, ao elogiar a Companhia Coimbra em sua primeira apresentação, é dito em relação ao espetáculo que, "no gênero, é uma das peças mais bem acabadas a que temos assistido ${ }^{25}$ ". A letra da peça, a fidelidade aos acontecimentos, a atuação de cada artista, foram mencionados e elogiados pelo jornal,

\footnotetext{
${ }^{24}$ BAT. Theatro. O Municipio. Diamantina. 21 Jan. 1899. n. 186. p. 4.
}

${ }^{25}$ Ibid. 
demonstrando assim a satisfação dos redatores com o ocorrido, o que levou o jornal a convidar a comunidade a assistir às apresentações da companhia que ainda estavam por vir.

Com essa primeira prova, podemos a bonar a companhia perante o publico de nossa cidade, que não perderá o seu tempo em procurar no theatro diversão ao espirito, como não perdem o que concorreu á estréa que cumulou os artistas de francos e justos applausos ${ }^{26}$.

Já em sua segunda apresentação, o público diamantinense se fez presente dentro e fora do teatro, o qual, tendo em vista a proximidade do mesmo com a igreja do Rosário dos Pretos permitia o envolvimento de outros estratos da população com os acontecimentos externos ao teatro. Helena Morley, em seu diário de memórias, que posteriormente foi convertido em livro, menciona que a porta do estabelecimento era um dos locais em que as negras libertas aproveitavam para obter alguma renda, "fazem pastéis de angu, sonhos e carajés para as festas de igreja e para a porta do Teatro" (MORLEY, 1999, p. 52).

Retomando à apresentação, a postura da comunidade foi elogiada pelo fato de não ter havido "confusão" apesar do grande número de pessoas presentes. Cabe ressaltar esse fato, tendo em vista que na cidade, o teatro era tido como uma diversão útil, a qual todos deveriam participar. Assim, a comunidade era convidada a estar presente nas apresentações, entretanto, quando um número expressivo de pessoas se fazia presente, havia o receio de que o comportamento não fosse como o desejado os levando a temer tumultos, algazarras e confusões.

No dia em questão foi apresentada uma opereta baseada na ópera francesa "Giroflé, Giroflá”; um drama de Alexandre Dumas Pai, “A Maldição Paterna” e a comédia "Uma Noite Perdida". "O desempenho foi bom por parte de todos os actores, que com justiça foram muito applaudidos" 27. A apresentação de 5 de fevereiro levou para o palco do Santa Isabel, as representações da "Revolução Pernambucana", que ocorreu em 1817, intitulada "Brazileiros e Portuguezes”, “original do ilustre brasileiro dr. Secundo Wanderley”. Mais uma vez o público se fez presente nos diferentes setores do teatro.

A companhia Coimbra teve um período extenso de apresentações na cidade de Diamantina. Nos comentários sobre as apresentações os redatores do periódico procuraram sempre informar sobre a atuação dos atores, quais peças foram apresentadas e sua autoria, revelando o interesse em levar ao leitor ainda mais conhecimento sobre o que se assistia na época e ao mesmo tempo dando credibilidade à companhia. Na apresentação de 11 de fevereiro de 1899, os redatores, no entanto, não conheciam a autoria das peças, mas não deixaram de

\footnotetext{
26 Ibid.

${ }^{27}$ BAT. Theatro. O Municipio. Diamantina. 30 Jan. 1899. n. 187. p. 1.
} 
falar a respeito e expressaram o que por eles era valorizado nas apresentações, como a linguagem dos personagens, a atuação dos atores, a ligação entre os fatos e, talvez, o mais importante para eles, o aspecto moral da peça.

Não conhecemos os autores das peças dramáticas; mas podemos affirmar que
são bem escriptas: têm bom estylo que, sem decahir, atende á gradação da
linguagem de cada personagem em seu papel; têm o enredo tecido de modo a
atender a ligação dos factos, sem deixar nenhum ponto obscuro; têm o fundo
moral e critico, em evidencia immediata para os espectadores, que, sem
esforço, percebem o ridículo de certas situações e o ridículo maior ainda dos
prejuízos sociaes, em casos vários, e de grande reproducção em toda parte ${ }^{28}$.

Esse destaque dado para o aspecto moral evidenciava para a plateia as situações de ridículo, as quais, segundo eles, possuíam o potencial de trazer prejuízos sociais, reafirma a posição do teatro na sua funcionalidade de escola dos. Mais uma vez os artistas foram elogiados pela qualidade da atuação e a companhia recomendada à população. "Quem procurar o theatro, não se arrependerá, porque, sem lisonja e sem encomenda, affirmamos: é de artistas a companhia Coimbra" ${ }^{29}$.

Ademais, a participação do público presente na apresentação foi enaltecida pela boa assistência e por não ter havido necessidade de intervenção policial, entretanto, mesmo com o constante incentivo, pode-se notar a queixa referente ao envolvimento da população com o teatro: "dois terços da cidade têm-se deixado ficar em casa, fazendo uma economia que não vem ao caso em uma terra de foguetórios e manifestações como a nossa, de índole eternamente talhada para o goso com sacrifício dos vinténs" ${ }^{30}$. Tal passagem evidencia um envolvimento abaixo do esperado por parte do público, bem como e o receio do comportamento dos presentes, tendo em vista que mais uma vez, foi destacado o fato de não ter havido confusão.

Aparentemente a companhia Coimbra mostrava-se conhecedora dos estilos teatrais em ascensão, como a apresentação de operetas. Sobre sua estadia, comentou o memorialista Ciro Arno ${ }^{31}$, "achava-se então em Diamantina, uma troupe de dramas e operetas, do Rio, a Companhia Coimbra, a primeira que representou naquela cidade norte-mineira (ARNO, 1942, p. 128)”. A menção feita de outro estado revela se tratar esta, uma companhia que saiu do Rio de Janeiro para Diamantina, a primeira no gênero das operetas a se apresentar na cidade, segundo o autor. Cabe ressaltar que na capital federal, Rio de Janeiro, tida como referência de

\footnotetext{
${ }^{28}$ Theatro. O Municipio. Diamantina. 17 de fevereiro de 1899, p. 3.

${ }^{29} \mathrm{Ibd}$.

${ }^{30} \mathrm{Ibd}$.

${ }^{31}$ Ciro Arno era pseudônimo de Cícero Arpino Caldeira Brant, bacharel pela faculdade de direito de São Paulo. Arno narrou parte de sua experiência enquanto estudante pelas cidades em que viveu, Diamantina, Ouro Preto, Belo Horizonte e São Paulo.
} 
modernidade adotada pelos periódicos locais, o início do teatro de revista, o qual contemplava as operetas remete ao final da década de 1850, o que demonstra que essa "modernidade", portanto, levou certo tempo para chegar a Diamantina (MARZANO, 2010).

Ciro Arno relata ainda a ida do estudante Lúcio, seu amigo, a um espetáculo da companhia Coimbra. Na ocasião, o rapaz havia decidido levar a família ao Teatro e, para tanto, resolveu alugar um camarote. Na noite em questão, a Companhia representava a comedia de Martins Pena Quem casa quer casa, seguida de um trecho da opereta Os sinos de Corneville. A banda Corinho tocava a abertura quando em seguida ouviram-se as três batidas anunciando o início da apresentação teatral, e o pano de cena foi erguido. "No palco: sala, com uma porta no fundo, duas à direita e duas à esquerda. Mesa, com folhas, papel, tinteiro, canetas, arceiro. Ao lado, seis cadeiras. Junto à porta da esquerda uma jovem (Paulina), no meio da sala uma matrona (Fabiana) (ARNO, 1942, p. 129)". As duas, nora e sogra, discutiam sobre quem deveria mandar na casa. Nesse momento, na porta de entrada da plateia,

dois rapazes se esmurravam. Apareceram alguns soldados, restabelecendo a ordem. Lá das torrinhas, uma voz trocista gritou:

_ Fabiana, sogra do diabo! Deixa tua nora em paz!_ Estalaram gargalhadas. [...] Na plateia, perto da orquestra, um sujeito gritou para o ponto:

_Sr. Ponto, leia mais baixo! Assim é intolerável!

Ergueu-se cambaleando. Dois vizinhos deram-lhe o braço e saíram com ele. Um sujeito das torrinhas berrou para a orquestra em baixo: maestro Paraguai: Oh Maestro Paraguai: Mande tocar "Saudades do Rio Vermelho"... é uma beleza (ARNO, 1942, p. 130)!

O maestro Paraguai deu o sinal, e a valsa foi tocada. Nesse relato de Ciro Arno, elementos do que se passava no teatro são revelados. Notando o aspecto educacional dos espetáculos, a peça em questão tinha o intuito de demonstrar quem deveria ser a dona do lar quando a nora morava junto a sogra. É possível notar também uma distinta forma de se portar nos diferentes espaços que o teatro oferecia ao público, estando os camarotes todos ocupados neste dia, nada que chamasse atenção ocorreu, ao passo que na plateia geral houve a narrada confusão entre os rapazes, bem como a interferência de outras pessoas nas histórias representadas pelos atores. Além disso, o público também intervinha com a programação, pedindo para que a banda tocasse músicas de sua preferência. A outra peça também apresentada não foi descrita como a primeira, mas é mencionada a presença de um garoto de recados que levara meia hora para "entrar no teatro" a fim de entregar um bilhete ao Lucio, fato que pode demonstrar, que esse, na verdade, teria aproveitado para assistir ao que se passava, para depois ir de fato até o camarote dar o recado sobre a saúde de sua madrasta. 
No penúltimo espetáculo do mês de fevereiro, Coimbra levou ao palco quatro comédias, na qual a primeira peça, Bertha de Castigo, apresentava a inocência de uma garota do colegial que tem uma aventura amorosa com um astucioso colega; a segunda, Estudante e uma Lavandeira, fez referências à Bahia, com suas danças, canções e pratos típicos; a terceira, Uma Criada Impagável, falava da "malandragem" entre patrão e criadas e por fim, Uma guerra às mulheres, que contou com gargalhadas intensas de Coimbra e canções de Hermínia, sua esposa. Sobre as peças foi dito que

não podia ser melhor o ultimo espectaculo, realizado pela acreditada companhia Coimbra.

Em seu inexgotavel repertorio, tirando a sorte, o Coimbra encontrou quatro comedias de truz, qual e qual melhor, todas bem acabadas, embebidas no espirito fino que se faz a contento de todos os paladares, temperadas com uns longes de naturalismo, inperceptiveis para o sexo innocente, e somente sensiveis á argucia maliciosa de alguns raros aprecciadores que, por indole, cutivam o genero.

$[\ldots]$

A companhia Coimbra é de artistas, merecendo todo o concurso da Diamantina que, por ser civilisada, deve dispensar toda a proteção a arte ${ }^{32}$.

A forma com a qual a peça foi elogiada pelos redatores, utilizando-se de metáforas, como na frase, "embebidas no espirito fino que se faz a contento de todos os paladares", reforça o teatro como divertimento digno e civilizado. Os redatores ressaltaram a reprodução de parte do cotidiano nas cenas apresentadas pela companhia e a ingenuidade do sexo feminino até mesmo na interpretação dos atos. Os artistas foram mais uma vez elogiados e a civilidade dos diamantinenses afirmada pela participação no evento artístico, privilégio dos citadinos.

O último fim de semana de fevereiro contou com a apresentação de uma opereta, intitulada Talismans do Amor, de autoria de Bittencourt e orquestrada pelos maestros Victor e Paraguai, a qual versou sobre o nordeste brasileiro colonial, tendo marchas, tangos e bailados populares do sertão envolvendo os personagens do Brasil e de Portugal. Nela foi narrado a história de um guarda-mor que se apaixona pela mais bela moça de sua capitania. No entanto, a moça tem amores por humilde rapaz, que não tem condições de pedir-lhe a mão em casamento. O jovem adquire de um feiticeiro três talismãs e uma varinha mágica, com os quais leva à humilhação o capitão-mor e obriga os pais da moça a consentir com o casamento. A peça se dividiu em três atos: O pedido do capitão-mor; Os Talismãs do Amor; e O mel não se fez para a boca do asno. No espetáculo em questão, foi comentado que os poucos ensaios prejudicaram a apresentação, mas que mesmo assim contou com a aprovação do público. Houve

\footnotetext{
32 Theatro. O Municipio. Diamantina, 27 de fevereiro de 1899, p. 3.
} 
ainda a representação do drama a Louca dos Pyreneus de autoria de d'Enery, que havia falecido há poucos dias em Paris, e que muito comoveu ao público presente ${ }^{33}$.

O mês de março contou com apresentações em benefício do descimento da Cruz, ato representado nas comemorações católicas na sexta-feira da paixão, e ao senhor Zeca Bento. Repetiu-se o drama A Louca dos Pyreneus e as peças Os dous surdos, a opereta Revista, baseada na poesia Gemeos e Martyres e o dueto Los Paraguas. "Ambos os espectaculos tiveram grande concurrencia e todos os actores desempenharam com correcção os seus papeis. A orchestra correspondeu aos esforços do seu digno regente professor Antonio Ephigenio de Souza" 34.

Em abril os benefícios das apresentações em dois dias distintos foram dados primeiro à senhora Herménia Coimbra, em que fora reapresentado a opereta Talismãs do Amor a pedido do público ${ }^{35}$, e à senhorita Sophia Bittencourt, com a reprise da "celebre opereta em 3 actos Mariquita-Maricota, imitada da opereta cômica Giroflé-Giroflá pelo Dr. Prazeres, com três actos e 21 numeros de musica de celebridades musicaes". A senhorita Sophia foi muito elogiada por sua atuação e eleita pelos redatores, como "uma das primeiras damas ingênuas do theatro nacional" que "tem conquistado justa nomeada em diversas cidades da Republica, desde Amazonas e Pará onde obteve bonitos triumphos até o nosso estado que tem acolhido como ella merece" 36 .

Ainda no mês de abril, com apenas três meses de estadia na cidade, o senhor Agostinho Pedra, integrante da companhia Coimbra, resolveu fixar residência na cidade, arrematando do Senhor Antônio Eulálio o restaurante e bilhar localizado no prédio do Hotel e Restaurante, na rua da Quitanda, posteriormente denominada rua Francisco Sá, no qual introduziu uma charutaria e um café ${ }^{37}$.

A regularidade de espetáculos ofertados pela companhia, geralmente realizados aos domingos e por algumas vezes nos sábados e domingos, se manteve com boa aceitação e recomendação nas colunas de $O$ Municipio. Na edição de número 199, logo na primeira página, a companhia Coimbra teve novamente destaque, em que foi comentada a presença do público que muito cedo chegou ao teatro para o último espetáculo dado, apresentando mais uma vez boas expectativas para as próximas apresentações:

é de se esperar que o publico desta cidade tão achegado as diversões da verdadeira arte, representada por verdadeiros artistas leve á companhia as

\footnotetext{
${ }^{33}$ Theatro. O Municipio. Diamantina, 04 de março de 1899, p. 3 e 4.

${ }^{34}$ Noticias - Theatro. O Municipio. Diamantina, 23 de março de 1899, p. 3.

${ }^{35}$ Noticias - Theatro. O Municipio. Diamantina. 15 de abril de 1899, p. 3.

${ }^{36}$ Noticias - Theatro. O Municipio. Diamantina. 22 de abril de 1899, p. 3.

${ }^{37}$ Noticias - Restaurant e Bilhares. O Municipio. Diamantina. 15 de abril de 1899, p. 2.
} 
expressões do seu real applauso, dando lhe uma casa que seja uma verdadeira enchente.

É preciso aproveitar porque tão cedo não se encontrará oportunidade tão feliz para recrear-se o espirito no meio de alegria e de uma paz, digna dos melhores elogios ${ }^{38}$.

Mais do que recomendar que os diamantinenses fossem prestigiar aquela companhia de "verdadeiros artistas", visto que tão cedo não haveria outra oportunidade, foi reafirmada a posição do diamantinense amante da arte e, o teatro como escola dos bons costumes, que recria o espírito, e era merecedor de sinceros aplausos e elogios.

Assim como os recorrentes elogios à companhia, o seu diretor também fora exaltado, não apenas por sua atuação no palco, mas também por sua personalidade e condição de chefe de família, demonstrando a boa relação que o mesmo desenvolvia com a cidade, bem como a sua adequação aos códigos sociais da época:

O velho Coimbra, provecto artista, que na vida intima é um chefe de família exemplar e na sociedade um perfeito cavalheiro, pelo seu caracter severo, pela nobreza de seus sentimentos, e pela sua fina educação, bem sabe as amizades que lhe ficam e que se estendem á sua exma, e virtuosa esposa, a seus interessantes filhinhos, a sua gentilíssima filha d. Sophia e a seu distincto genro o Sr. Bittencourt ${ }^{39}$.

\section{A Companhia Coimbra e o Teatro de Amadores}

Entre a partida de uma companhia de teatro ambulante e a chegada de outra, grupos locais se destacavam pela sua atuação no Teatro Santa Isabel como forma de dar continuidade àqueles momentos de divertimento e de manter em atividade a "escola dos bons costumes". Era comum que as cidades buscassem combater a precariedade das instalações dos teatros com a utilização das rendas obtidas com as apresentações de amadores. "Buscava-se, assim, tornar a localidade mais atraente para as companhias ambulantes, oferecendo melhores acomodações e demonstrando apreço pela arte dramática” (DUARTE, 1995, p. 156), uma vez que colocava em evidencia o esforço da comunidade para manter um local destinado às apresentações teatrais e demonstra a demanda do público, já “educado” para assistir às apresentações.

Em Diamantina, dois grupos de amadores tiveram destaque nas páginas dos jornais. $\mathrm{O}$ Recreio Dramático, inicialmente criado em 1892, mas com atuação efetiva entre 1896 e 1898, e retomado em dezembro de 1899, com o nome de Progresso da Mocidade, com atuação até o ano de 1903. O outro grupo, criado com parte do elenco do Recreio Dramático e com os

\footnotetext{
${ }^{38}$ Noticias - Companhia Coimbra. O Municipio. Diamantina, 26 de maio de 1899, p. 1.

${ }^{39}$ Noticias - Theatro. O Municipio. Diamantina, 30 de dezembro de 1899, p. 3.
} 
integrantes da Companhia Coimbra, denominado Companhia Coimbra de Amadores, teve atuação entre os meses de julho a outubro de 1899.

A companhia Coimbra, organisada nesta cidade com distinctos amadores, realizou o seu segundo espectaculo no dia 2 do andante, levando a scena o surprehendente drama em 3 actos, um primor da litteratura dramatica franceza, composição de Alexandre Dumas - Condessa Siana de Rione ${ }^{40}$.

Como se pode ver, após seis meses com apresentações regulares no Teatro Santa Isabel, a companhia Coimbra reuniu diamantinenses e criou uma companhia de amadores para atuarem no teatro local. Nessa segunda apresentação, o grupo representou a peça Condessa Siana de Rione, do importante romancista francês Alexandre Dumas. Na ocasião, houve alguns desentendimentos entre os amadores devidos a problemas na atuação, enquanto os atores veteranos da companhia foram bastante aplaudidos. Na atuação dos amadores destacaram-se Mundinho, Zinho, Sálvio e Fino.

O Mundinho e o Zinho, por sua vez, um no difícil papel de galã, outro de baixo comico, mostraram ter avançado muito em escola e gosto.

Salvio e Fino receberam mais uma aproveitável licção que servir-lhes-á de certo para perderem senões, explicáveis e toleráveis na difícil arte ${ }^{41}$.

A noite foi finalizada com a representação da comédia Os Três Castiçais, do também francês Victor Bernard, com atuação apenas dos veteranos. "No mais: ordem, harmonia, e as mais pronunciadas provas de sympathia pela companhia que dirige o intelligente hospede", o Coimbra $^{42}$.

No dia 23 de julho a companhia de Amadores Coimbra realizou a terceira apresentação na cidade, com a representação da opereta "O Milagre e O Pomba”, que foi muito aplaudida pelo público, momento em que os mesmos já se preparavam para em breve apresentar o drama sacro Santa Angela ${ }^{43}$. Dois dias após essa apresentação, a Câmara Municipal da cidade decretou a lei de número 94, que tinha como finalidade revogar a lei $\mathrm{n}^{\circ} 36$ de 16 de julho de 1896, a qual era previsto um aporte financeiro "annual de $600 \$$ a qualquer companhia dramática que se crear nesta cidade" ${ }^{44}$. Tal fato nos faz levantar a hipótese, tendo em vista principalmente por ocorrer após apenas duas apresentação da companhia amadora, de que essa ação poderia indicar uma estratégia do governo municipal para que a companhia, na pessoa do Coimbra, continuasse com o pagamento de impostos por apresentação, não recebendo assim subsídios do município, uma vez que não se tratava de uma companhia formada apenas por diamantinenses.

\footnotetext{
40 Theatro. O Municipio. Diamantina, 05 de julho de 1899, p. 3.

${ }^{41}$ Theatro. O Municipio. Diamantina, 05 de julho de 1899, p. 3

42 Ibid.

${ }^{43}$ Noticias. O Municipio. Diamantina, 29 de julho de 1899, p. 3.

${ }^{44}$ Lei $\mathrm{n}^{\circ} 94$ de 25 de Julho de 1899. O Municipio. Diamantina, 29 de julho de 1899, p. 1.
} 
No mês de setembro a companhia Coimbra apresentou pela quarta vez, dessa vez sem a presença dos atores amadores, a opereta Talismãs do Amor, de autoria de Luiz Bittencurt. Os elogios dados à companhia remetem "a concurrencia numerosa que as suas recitas teem tido, mercê do bom grupo de artistas de que ella se compõe e de seu excellente e inesgotável repertorio" 45 . Foi narrada ainda as dificuldades apresentadas no espetáculo, tendo em vista que as músicas utilizadas, de autoria do diamantinense José de Altamiras, não saíram como o esperado, o que, segundo o maestro Paraguay poderiam ser facilmente resolvidas com "o tempo e maior numero de ensaios". Assim, o jornal reconheceu as falhas destacando a dificuldade da execução, o pouco tempo de preparo.

Essa pressa na montagem da peça por Coimbra pode se justificar pelo fato da companhia estar se retirando da cidade com destino a Itabira, após dez meses de estadia na cidade. Em agradecimento aos munícipes a companhia Coimbra dedicou o último espetáculo ao Asilo de Inválidos que funcionava há dez anos, mas com dificuldades de manutenção, e era administrado pela Santa Casa, assim como o teatro.

Para prova de sua gratidão, estimulado pelo amor ao bem, e pelo pedido da benemerita commissão que tem sobre seus hombros a gloriosa empresa da fundação de um Asylo de Invalidos nesta cidade, resolveu o nobre artista trabalhar no ultimo espectaculo, consagrando o fructo do mesmo em beneficio do Asylo.

É de um dever elementar acudirem todos ao espectaculo, concorrendo assim para a execução de uma idéa que fará crescer o nosso nome entre as cidades de nosso estado mais recommendaveis pelo seu progresso.

Alem desse dever que é de todos, pensamos ser das regras so cavalheirismo e da hospitalidade bem entendida, ouvirmos o Coimbra em seu ultimo trabalho e apresentarmos a elle e a sua digna familia as nossas despedidas ${ }^{46}$.

O progresso de Diamantina é mencionado dessa vez não apenas pelo gosto pelas artes e pela hospitalidade do diamantinense, mas principalmente por ter a cidade um asilo destinado ao acolhimento dos pobres e desvalidos, prática das cidades "modernas" que prezavam pela saúde pública. Em 28 de outubro de 1899 a companhia deixou a cidade com destino a Itabira. Foi lembrado que a companhia "proporcionou muitas noutes de agradabilíssimas diversões, sendo justamente aplaudida" 47 e recomendada aos itabiranos que a recebessem com o acolhimento que lhe era peculiar.

Com a retirada da família Coimbra, a companhia Coimbra de Amadores acabou se desfazendo, tendo um período de atuação curto, de julho a outubro de 1899. Com o anúncio da

\footnotetext{
${ }^{45}$ Noticias - Theatro. O Municipio. Diamantina, 04 de setembro de 1899, p. 3.

${ }^{46}$ Ibid.

${ }^{47}$ Noticias - Companhia Coimbra. O Municipio. Diamantina, 06 de novembro de 1899, p. 3.
} 
retirada de Coimbra, esse tem destaque na edição de $O$ Municipio, em que, "com somma enorme de sacrificios, trouxe a nossa cidade, este distincto actor pernambucano cujo nome muito se recommenda pelo exercicio afanoso da arte dramatica em diversas cidades da Republica", e completado que

durante 8 mezes, trabalhou o insigne artista no theatro de S. Isabel: durante esse longo tempo gastou elle dinheiro, trabalho, paciencia para nos ministrar o que de melhor teve em seu repertorio, recheado de dramas, comedias e operetas; ensinou as suas lições a diversos moços, alguns dos quaes estão a trabalhar com as melhores figuras dos amadores e entretanto a sua compensação foi nella, devida a citada crise que, com mais força de razão, ataca as artes em geral ${ }^{48}$.

Em 1903 chega a Diamantina a notícia de que falecera na cidade de Cachoeiro do Itapemirim, no estado do Espírito Santo, o artista Coimbra. O Municipio dedicou parte da edição para contar a trajetória deste artista. A estadia de Coimbra foi lembrada pelos numerosos elogios que recebeu da imprensa diamantinense, tendo destaque não só ele como sua esposa e sua filha. Coimbra dizia aos amigos de Diamantina "tenho fé em Deus que em breve serei chamado a uma vida melhor" ${ }^{49}$, demonstrando o seu cansaço pela vida como ator ambulante.

\section{Considerações finais}

A Companhia Coimbra, ocupou um significativo espaço entre as páginas do jornal $O$ Município. Dessa forma, foi possível perceber que o público era envolvido com uma regularidade de apresentações ao longo dos meses. A plateia se envolvia nos diferentes espetáculos manifestando seu agrado ou não com palmas, vaias e pedidos para que suas preferências musicais fossem atendidas. Em algumas poucas exceções, foi possível notar trechos no jornal em que havia a queixa da ausência de famílias diamantinenses nas atividades do teatro. Nas demais referências às apresentações da companhia são relatadas que o público se fez presente na medida em que os lugares estiveram disponíveis, o que demonstra que parte da elite diamantinense frequentava o teatro menos do que era esperado, indício de que na prática a participação não era tão efetiva quanto no discurso.

Os jovens diamantinenses subiram aos palcos levando certa dinamicidade aos espetáculos exibidos no teatro Santo Isabel. Tendo em vista que a Companhia Coimbra foi responsável pelos ensinamentos do segundo grupo de amadores a ser formado na cidade, o que

\footnotetext{
${ }^{48}$ Antonio Coimbra. O Municipio. Diamantina, 02 de outubro de 1899, p. 1.

${ }^{49}$ BAT. Antonio Coimbra. O Municipio. Diamantina. 18 Nov. 1903. n. 308. p. 2.
} 
demonstra a relevância que tal companhia teve no sentido de fomentar a vida artística e cultural local.

As representatividades levantadas neste trabalho possibilitaram outros questionamentos e outras possibilidades de se conhecer ainda mais a sociedade diamantinense por meio de seus divertimentos. Dessa forma, entende-se que esta pesquisa abre portas para futuros questionamentos que possam suscitar outros trabalhos a fim permitirem uma melhor compreensão da dinâmica dos divertimentos, em especial na área do teatro, não só de Diamantina, mas também em outras cidades, principalmente as mais afastadas dos grandes centros, muitas vezes colocadas à margem nas pesquisas acadêmicas.

\section{Referências bibliográficas}

ALVES, R. O. T. "Da ponta dos trilhos ao centenário inventado": práticas modernas de divertimento em Montes Claros - MG (1926-1957). Belo Horizonte: Tese (doutorado) Universidade Federal de Minas Gerais, Escola de Educação Física, Fisioterapia e Terapia Ocupacional, 2018.

ANDRADE, A. L. V. D.; BULHÕES, A. M. D. A Mulher e o Teatro Brasileiro do século XX. São Paulo: Aderaldo \&Rotschild, 2008.

ARNO, C. Memórias de Um Estudante. Belo Horizonte: [s.n.], 1942.

BASTOS, A. D. S. Carteira do Artista. Lisboa: Bertand, 1898.

BRAGA, C. Em Busca da Brasilidade: teatro brasileiro na primeira república. São Paulo: Perspectiva, 2003.

DUARTE, R. H. Noites Circenses: espetáculos de circo e teatro em Minas Gerais no século XIX. Campinas, SP: Editora da UNICAMP, 1995.

GODWIN JUNIOR, J. W. Cidades de Papel: imprensa, progresso e tradição: Diamantina e Juiz de Fora, MG (1884-1914). Belo Horizonte: Fino Traço, 2015.

LOBATO, M. M. A Presença da Fábrica no "Grande Empório do Norte": surto industrial em Diamantina entre 1870 e 1930. Semniário Sobre Economia Mineira, 9 Anais. Cedeplar, Belo Horizonte, 2000.

MARZANO, A. A Magia dos Palcos: o teatro no Rio de Janeiro do século XIX. In: MARZANO, A.; MELO, V. A. D. Vida Divertida: história do lazer no Rio de Janeiro (18301930). Rio De Janeiro: Apicuri, 2010. p. 97-124.

MARZANO, A.; MELO, V. A. D. Vida Divertida: história do lazer no Rio de Janeiro (18301930). Rio de Janeiro: Apicuri, 2010.

MORLEY, H. Minha Vida de Menina. São Paulo: Companhia das Letras, 1999.

OLIVEIRA, R. C. S. D. O Teatro e Algumas Diversões em Diamantina: uma história registrada pela imprensa (1888-1915). Belo Horizonte: Dissertação (mestrado) - Universidade Federal de Minas Gerais, Escola de Educação Física, Fisioterapia e Terapia Ocupacional, 2016. PRADO, D. D. A. O Teatro Brasileiro Moderno. São Paulo : Perspectiva, 2001.

SANTOS, D. L. S. Cidades de vidro: a fotografia de Chichico Alkmim e o registro da tradição e da mudança em Diamantina: 1900 a 1940. Belo Horizonte: Tese (doutorado) - Universidade Federal de Minas Gerais, Faculdade de Filosofia e Ciências Humanas. 330 fl.: il. 2015, 2015. VENEZIANO, N. O Teatro de Revista no Brasil: dramaturgia e convenções. Campinas: Pontes: Editora da Universidade Estadual de Campinas, 1991. 